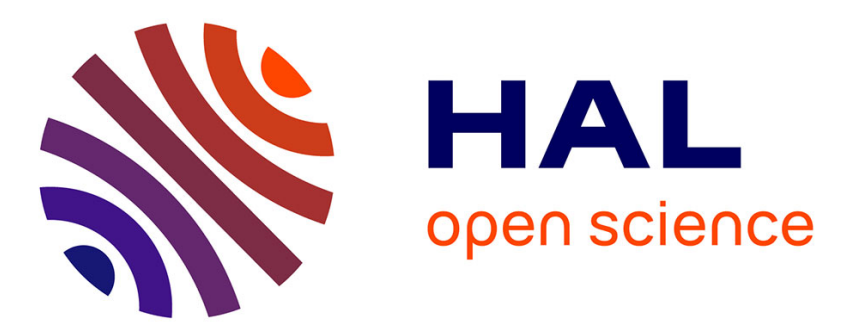

\title{
Isotropic and anisotropic descriptions of damage in concrete structures
}

Stéphanie Fichant, Christian La Borderie, Gilles Pijaudier-Cabot

\section{To cite this version:}

Stéphanie Fichant, Christian La Borderie, Gilles Pijaudier-Cabot. Isotropic and anisotropic descriptions of damage in concrete structures. Mechanics of Cohesive-frictional Materials, 1999, 4 (4), pp.339359. 10.1002/(SICI)1099-1484(199907)4:43.0.CO;2-J . hal-01007002

\section{HAL Id: hal-01007002 https://hal.science/hal-01007002}

Submitted on 31 Jul 2017

HAL is a multi-disciplinary open access archive for the deposit and dissemination of scientific research documents, whether they are published or not. The documents may come from teaching and research institutions in France or abroad, or from public or private research centers.
L'archive ouverte pluridisciplinaire HAL, est destinée au dépôt et à la diffusion de documents scientifiques de niveau recherche, publiés ou non, émanant des établissements d'enseignement et de recherche français ou étrangers, des laboratoires publics ou privés.

\section{(c)(1)}

Distributed under a Creative Commons Attribution| 4.0 International License 


\title{
Isotropic and anisotropic descriptions of damage in concrete structures
}

\author{
Stéphanie Fichant, Christian La Borderie and Gilles Pijaudier-Cabot \\ Laboratoire de Mécanique et Technologie, ENS Cachan/CNRS/Universite\& P. et M. Curie, 61 avenue du Président Wilson, \\ F-94235 Cachan cedex, France
}

Scalar damage models are very often implemented in computational analyses in order to predict the response and failure modes of concrete and reinforced concrete structures. In most situations, however, damage is not isotropic but has preferential directions. Therefore, there have been many questions about the pertinence and range of applicability of isotropic, scalar, damage models for describing a degradation process which is strongly geometrically oriented. In order to assess what are the limitations of such a simplifying assumption, a comparative study is presented. The constitutive relations used for this purpose derive from the same class of models with a gradual enhancement of the description of damage. The scalar damage model is compared to another model where damage-induced orthotropy is described, with the possibility of rotation of the principle axes of orthotropy. Both models incorporate crack closure effects and a plasticity damage coupling. Structural analyses on bending beams, compression-shear and tension-shear concrete panels are presented. Although it may appear to be simplistic, the scalar damage model provides accurate predictions when failure is mainly due to uniaxial extension. Crack closure introduces an additional anisotropy which is important in compression-shear problems. Finally, damage-induced anisotropy seems important when failure is due to multiaxial extensions, such as in shear-tension problems.

KEY WORDS: continuum damage; anisotropy; isotropy; failure analysis

\section{INTRODUCTION}

Quasi-brittle materials such as concrete exhibit a non-linear stress-strain response mainly because of microcracking. In most cases, these microcracks are oriented with respect to the applied stress history: ${ }^{1,2}$ in uniaxial tension, microcracks develop perpendicularly to the tensile stress; in compression, splitting cracks parallel to the direction of the compressive stress appear. The development of microcracks results in a progressive degradation of the elastic stiffness of the material. If the material is initially isotropic, the degraded elastic operator is not expected to remain isotropic but to become gradually anisotropic. This phenomenon is called damageinduced anisotropy because anisotropy of the elastic response of the material evolves with damage.

The damage variable defined first by Kachanov was essentially one-dimensional although it has been extensively applied in the three-dimensional context, assuming that damage does not 
induce anisotropy. ${ }^{3}$ Several anisotropic damage models have been developed for quasi-brittle materials. Among many proposals, Krajcinovic and Fonseka ${ }^{4}$ used damage vectors, Sidoroff, ${ }^{5}$ Chaboche et al., ${ }^{6}$ Mazars and Pijaudier-Cabot, ${ }^{7}$ Dragon and Mroz, ${ }^{8}$ Berthaud et al., ${ }^{9}$ and Valanis ${ }^{10}$ used a second-order tensor, Ortiz, ${ }^{11}$ Simo and $\mathrm{Ju},{ }^{12}$ Yazdani and Schreyer, ${ }^{13}$ and recently Carol et al. ${ }^{14}$ and Govindjee et al. ${ }^{15}$ proposed to consider that damage is a fourth-order tensor. Note that smeared crack models such as those devised by Rots ${ }^{16}$ could be also considered as damage models where the damage variable is a fourth-order tensor.

The variety of such proposals is somewhat puzzling because (i) the relation between each model is difficult to establish (except may be when damage is indeed isotropic) and (ii) it is difficult to compare the predicted type of damage-induced anisotropy with experimental data and therefore to provide a proper method for choosing the most appropriate type of damage variable. A full characterization of the damage-induced anisotropy of the material requires three-dimensional experimental facilities and means of analysis which are, to our knowledge, only in the process of being developed. ${ }^{17}$

It seems appropriate that rational methods for the derivation of the type of damage variable should be devised in order to achieve a proper understanding of the type of damage variable to be used for a given material. Ladeveze ${ }^{18}$ proposed a general technique of approximation of the elastic stiffness of a damaged material. The method introduces two damage surfaces which characterise the unidirectional stiffness and the compressibility of the material for any loading direction. The elastic moduli are derived using an approximation technique which is similar to a weighted residual method. In Ladeveze's proposal, it is already stated that the definition of the damage surfaces should be envisioned with respect to experimental observations: without any other discriminating data, the simple knowledge of a uniaxial response of the material (axial strain-axial stress) cannot provide anything but a one scalar isotropic damage model. For the same experiment, the additional knowledge of the axial strain vs. transverse strain curve yields a two scalar isotropic damage model.

Although it is purely phenomenological, this method relates the local state of damage in each direction to the overall mechanical response of the material. Another interesting method is the microplane approach proposed for quasi-brittle materials e.g. by Bazant and Ozbolt. ${ }^{19}$ The elastic (or tangent) stiffness of the material is obtained from the relationship between the stress and the strain vectors for any arbitrary microplane direction. The construction of the stiffness results from an energy-based equivalence. Damage is defined at the microplane level and the relation with the global elastic stiffness of the material was elucidated by Carol et al. ${ }^{20,21}$ They arrived at the definition of a fourth-order damage tensor where the damage variables at the microplane level appear. Hence, it is possible to relate the local directional damage to the global degradation of the elastic properties of the material. Fichant et al. ${ }^{22}$ combined the simple features of the microplane approach with the approximation of damage surfaces in the same spirit as Ladeveze's approach. They derived a simplified microplane-type model where the behaviour of the damaged material is discretized along a finite set of directions and interpolated in between them. The elastic behaviour of the damaged material depends on the interpolation used for the distribution of damage in each direction of the material. With an infinite number of discretization directions, the microplane model is recovered.

In view of the simplicity of implementation of a scalar model, it can be appealing to disregard the crack orientation, provided the numerical prediction does not really differ from those of a more realistic model which incorporates damage-induced anisotropy. In this paper, we will focus attention on this issue and we will try to sort out the cases where a simple, scalar approach 
yields sufficiently accurate results. The approximation method devised by Fichant will provide a preferential setting for an objective comparison because different approximation levels can be considered on the basis of the same model parameters which are given by the same experiments. After having briefly recalled the principles of this approximation, we shall first present the constitutive model with damage-induced anisotropy which will be considered. Crack closure effects and the inherent stiffness recovery will be also introduced because we will see that they yield an additional kind of anisotropy. The remaining part of the paper will be devoted to comparisons between the isotropic and anisotropic damage models from the viewpoint of structural analysis.

\section{PRINCIPLE OF THE CONSTITUTIVE MODEL}

The models that are going to be compared are based on the approximation of the relationship between the overall stress (later simply denoted as stress) and the effective stress in the material defined by the equation:

$$
\sigma_{i j}^{t}=C_{i j k l}^{0} \varepsilon_{k l} \text { or } \sigma_{i j}^{t}=C_{i j k l}^{0}\left(C^{\text {damaged }}\right)_{k l m n}^{-1} \sigma_{m n}
$$

where $\sigma_{i j}$ is the overall stress components, $\sigma_{i j}^{t}$ is the effective stress component, $C_{i j k l}^{\text {damaged }}$ is the stiffness of the damaged material, and $C_{i j k l}^{0}$ is the initial stiffness of the undamaged material, assumed to be isotropic, linear and elastic. Let us define the relationship between the stress and the effective stress along a finite set of directions of unit vectors $n$ at each material point:

$$
\begin{aligned}
\sigma & =(1-d(n)) n_{i} \sigma_{i j}^{t} n_{j} \\
\tau & =(1-\delta(n)) \sqrt{\sum_{i=1}^{3}\left(\sigma_{i j}^{t} n_{j}-\left(n_{k} \sigma_{k l} n_{l}\right) n_{i}\right)^{2}}
\end{aligned}
$$

where $\sigma$ and $\tau$ are the normal and tangential components of the stress vector, respectively, and two damage surfaces are introduced:

$$
S_{d}(n): n \rightarrow d(n) \text { and } S_{\delta}(n): n \rightarrow \delta(n)
$$

$d(n)$ and $\delta(n)$ are scalar valued quantities which introduce the effect of damage. The basis of the model is the numerical interpolation of these surfaces which are approximated by the knowledge of $d(n)$ and $\delta(n)$ for a finite set of directions. ${ }^{22,23}$

The stress is solution of the virtual work equation:

find $\sigma_{i j}$ such that $\forall \varepsilon_{i j}^{*}$

$$
\frac{4 \pi}{3} \sigma_{i j} \varepsilon_{i j}^{*}=\int_{s}\left(\left[(1-d(n)) n_{k} \sigma_{k l}^{t} n_{l} n_{i}+(1-\delta(n))\left(\sigma_{i j}^{t} n_{j}-n_{k} \sigma_{k l}^{t} n_{l} n_{i}\right)\right] \cdot \varepsilon_{i j}^{*} n_{j}\right) \mathrm{d} \Omega
$$

The model is similar to a microplane model which is kinematically constrained. ${ }^{19}$ The most important difference with the microplane model is that in the absence of damage, equation (4) yields exactly the stiffness matrix of an isotropic material, without the need for integrating. From now on, we will consider that the two damage surfaces are identical: $d(n)=\delta(n)$. If the damage surface remains spherical, isotropy of the material is preserved. The simplest approximation which does not yield isotropy corresponds to an ellipsoidal damage surface: this surface is 
characterized by three principal directions and by the values of three damage scalars $d_{i}$ along these directions.

We are now going to detail the anisotropic damage model. In this model we will assume that the damage surface is ellipsoidal. The isotropic damage model will be deduced from the anisotropic one simply by assuming that the damage surface is spherical instead of being ellipsoidal.

\section{ANISOTROPIC PLASTIC-DAMAGE MODEL}

Degradation of the stiffness due to progressive microcracking is one among several important features of the behaviour of concrete. The stiffness degradation occurs mainly for tensile loads. Hence, the evolution of damage will be indexed on tensile strains. In compression or tension-shear problems, plastic strains are also of importance and will be added in the model. When the loading history is not monotonic, damage deactivation occurs due to microcrack closure. Since we intend to investigate and to compare the response of damage models to different loading histories, it seems important to describe this phenomenon.

\subsection{Evolution of damage}

The evolution of the elastic constants due to damage growth is given by the evolution of the damage surfaces. Initially, the damage surface (Equation (3)) is reduced to a point $d(n) \equiv 0$. Once damage starts to grow, it becomes an ellipsoidal surface. The evolution of damage is controlled by a loading surface $f$ :

$$
f(n)=n \varepsilon^{\mathrm{e}} n-\varepsilon_{\mathrm{d}}-\chi(n)
$$

where $\varepsilon^{\mathrm{e}}$ denotes the elastic strain, $\chi$ is a hardening softening variable which is interpolated in the same fashion as the damage surface. The threshold of damage is given by the strain $\varepsilon_{\mathrm{d}}$. The evolution of the damage surface is defined by an evolution equation inspired from that of an isotropic model: ${ }^{7}$

$$
\begin{aligned}
& \text { if } f\left(n^{*}\right)=0 \text { and } n^{*} \mathrm{~d} \varepsilon^{\mathrm{e}} n^{*}>0 \\
& \text { then }\left\{\begin{array}{l}
\mathrm{d} d\left(n^{*}\right)=\left[\frac{\varepsilon_{\mathrm{d}}\left(1+a\left(n^{*} \varepsilon^{\mathrm{e}} n^{*}\right)\right)}{\left(n^{*} \varepsilon^{\mathrm{e}} n^{*}\right)^{2}} \exp \left(-a\left(n^{*} \varepsilon^{\mathrm{e}} n^{*}-\varepsilon_{\mathrm{d}}\right)\right] n^{*} \mathrm{~d} \varepsilon^{\mathrm{e}} n^{*}\right. \\
d \chi\left(n^{*}\right)=n^{*} \mathrm{~d} \varepsilon^{\mathrm{e}} n^{*}
\end{array}\right. \\
& \text { else } \mathrm{d} d\left(\bar{n}^{*}\right)=0, \quad d \chi\left(n^{*}\right)=0
\end{aligned}
$$

The model parameters are $\varepsilon_{\mathrm{d}}$ and $a$. Note that the vectors $n^{*}$ are the three principal directions of the incremental strain whenever damage grows. The new damage surface is the combination of two ellipsoidal surfaces: the one corresponding to the initial damage surface, and the ellipsoid corresponding to the incremental growth of damage. Hence, the principal directions of the overall stress are not necessarily the same as the principal directions of the strain.

In the isotropic damage model, the same evolution of damage will be implemented, with a different, spherical, approximation of the damage surface (the radius of the sphere grows with damage). It is important to remark that the model parameters in the evolution laws of damage do not depend on the level of interpolation. In the comparisons, this characteristic will be essential 
because any discretisations of the damage surface provide exactly the same uniaxial material response in tension.

\subsection{Coupling with plasticity}

Plasticity can be introduced at several levels. In the microplane approach, plasticity is coupled to damage at the microplane level. ${ }^{24}$ In other phenomenological models, ${ }^{25,26}$ the coupling between damage and plasticity is introduced in the definition of the free energy of the material. Because we wish to separate the approximation of damage from plasticity, we will use the second technique. Locally, plasticity (microcracks sliding) and damage (microcrack opening) are assumed to be uncoupled as far as their evolution is concerned. This assumption introduces also a great simplicity in the computational implementation. ${ }^{25,27}$

We decompose the strain increment in an elastic and plastic one:

$$
\mathrm{d} \varepsilon_{i j}=\mathrm{d} \varepsilon_{i j}^{\mathrm{e}}+\mathrm{d} \varepsilon_{i j}^{\mathrm{p}}
$$

Damage is introduced in the elastic part of the stress-strain response

$$
\sigma_{i j}=C_{i j k l}^{\text {damaged }} \varepsilon_{k l}^{\mathrm{e}}
$$

and the elastic strain is substituted to the total strain in equation (1). We assume that the evolution of the plastic strain is controlled by a yield function which is expressed in terms of the effective stress in the undamaged material. Among the various possibilities in the choice of a yield function, we have chosen to implement a yield function due to $\mathrm{Nadai}^{28}$ inspired from the Drucker-Prager criterion. This choice is somewhat arbitrary and may not be totally realistic. We do not intend, however, to focus on a specific elastoplastic damage model which would be as general as possible but rather to compare two of them. As we will see further, this yield function provides a sufficiently accurate approximation of the response of the material to uniaxial tension/compression loads. The Nadai yield function is the combination of two Drucker-Prager functions $F_{1}$ and $F_{2}$ with the same hardening evolution:

$$
F_{i}=\sqrt{\frac{2}{3} J_{2}^{t}}+A_{i} \frac{I_{1}^{t}}{3}-B_{i} w
$$

where $J_{2}^{t}$ and $I_{1}^{t}$ are the second invariant of the deviatoric effective stress and the first invariant of the effective stress, respectively. $w$ is the hardening variable and $\left(A_{i}, B_{i}\right)$ are four parameters $(i=1,2)$ which are related to the ratios of the tensile strength to the compressive strength denoted $\gamma$ and of the biaxial compressive strength to the uniaxial strength denoted $\beta$ :

$$
A_{1}=\sqrt{2} \frac{1-\gamma}{1+\gamma}, A_{2}=\sqrt{2} \frac{\beta-1}{2 \beta-1}, B_{1}=2 \sqrt{2} \frac{\gamma}{1+\gamma}, B_{2}=\sqrt{2} \frac{\beta}{2 \beta-1}
$$

Because damage may also affect the overall response of the material in the hardening regime, the meaning of the ratios $\gamma$ and $\beta$ is slightly changed. For instance, damage may have already developed when the material peak stress is reached, e.g. in compression and can modify its value. In the models, these two ratios will be kept constant: $\beta=1.16$ and $\gamma=0.4$.

The evolution of the plastic strain is associated to these surfaces. The hardening rule is given by

$$
w=q p^{r}+w_{0}
$$


where $q$ and $r$ are model parameters, $w_{0}$ defines the initial reversible domain in the stress space, and $p$ is the effective plastic strain.

\subsection{Crack closure effects}

Crack closure effects are of importance when the material is subjected to alternated loads. During load cycles, microcracks close progressively and the tangent stiffness of the material should increase while damage is kept constant.

A decomposition of the stress tensor into a positive and negative part is introduced:

$$
\sigma=\langle\sigma\rangle^{+}+\langle\sigma\rangle^{-}
$$

where $\langle\sigma\rangle^{+}$and $\langle\sigma\rangle^{-}$are the positive and negative parts of the stress tensor (for a scalar $\langle x\rangle^{+}=x$ if $x>0$ and $\langle x\rangle^{+}=0$ if $x<0$ ). This decomposition was first used by Ladeveze ${ }^{18}$ and Ortiz $^{11}$ in order to introduce damage deactivation and the influence of the sign of the stresses on the material response. The relationship between the stress and the effective stress defined in equation (2) of the model is modified:

$$
\sigma_{i j} n_{j}=(1-d(n))\langle\sigma\rangle_{+i j}^{t} n_{j}+\left(1-d_{\mathrm{c}}(n)\right)\langle\sigma\rangle_{-i j}^{t} n_{j}
$$

$d_{\mathrm{c}}(n)$ defines a new damage surface which describes the influence of damage on the response of the material in compression. Because this new variable refers to the same physical state of degradation as in tension, there is a relation between $d_{\mathrm{c}}(n)$ and $d(n)$. The new damage surface defining $d_{\mathrm{c}}(n)$ is directly deduced from the damage surface $d(n)$. It is defined by the same interpolation as $d(n)$ and along each principal direction $i$, we have the relation:

$$
d_{\mathrm{c}}^{i}=\left(\frac{d_{j}\left(1-\delta_{i j}\right)}{2}\right)^{2}, \quad i \in[1,3]
$$

where $\delta_{i j}$ is the kronecker symbol and $\alpha$ is a model parameter.

\subsection{Response of the model and computational aspects}

For the isotropic and anisotropic models, the constitutive relations contain six parameters in addition to the Young's modulus of the material and the Poisson's ratio. The first series of three parameters $\left(\varepsilon_{\mathrm{d}}, a, \alpha\right)$ deals with the evolution of damage. Their determination benefits from the fact that in tension, plasticity is negligible, hence $\varepsilon_{\mathrm{d}}$ and $a$ are directly deduced from a uniaxial tension test. If we assume that in uniaxial tension damage starts once the peak stress is reached, $\varepsilon_{\mathrm{d}}$ is the uniaxial tensile strain at the peak stress. $a$ is much more difficult to obtain because the model exhibits strain softening. In order to circumvent some of the difficulties involved with softening in the computations, we have chosen to control that the energy dissipation due to cracking in uniaxial tension be constant whatever the finite element size. ${ }^{16,29}$ Therefore, $a$ becomes an element related parameter and it is computed from the fracture energy. For a linear displacement interpolation, $a$ is solution of the following equality where the states of strain and stresses correspond to uniaxial tension:

$$
h \phi=G_{\mathrm{f}}, \text { with } \phi=\int_{0}^{\infty} \int_{\Omega}\left[\dot{d}(\mathbf{n}) \mathrm{n}_{k} \sigma_{k l}^{t} n_{l} n_{i}\right] n_{j} \mathrm{~d} \Omega \mathrm{d} \varepsilon_{i j}
$$


$\phi$ is the energy dissipation per unit volume, $G_{\mathrm{f}}$ is the fracture energy and $h$ is related to the element size (square root of the element surface in a two-dimensional analysis with a linear interpolation of the displacements). According to equation (6), $a$ appears in the rate of damage in (15). It is the only unknown in this equation. All the other parameters in equation (15) are known (damage threshold and strain path).

The third model parameter $\alpha$ enters in the influence of damage created in tension on the compressive response of the material. Once the evolution of damage in tension has been fitted, this parameter is determined by plotting the decrease of the uniaxial unloading modulus in a compression test vs. the growth of damage in tension according to the model. In a log-log co-ordinate system, a linear regression yields the parameter $\alpha$.

The second series of three parameters involved in the plastic part of the constitutive relation is $\left(q, r, w_{0}\right)$. They are obtained from a fitting of the uniaxial compression response of concrete once the parameters involved in the damage part of the constitutive relations have been obtained.

Figure 1 shows a typical uniaxial compression-tension response of the model corresponding to a standard concrete with a tensile strength of $3 \mathrm{MPa}$ and a compressive strength of $40 \mathrm{MPa}$. The set of model parameters is

$E=30000 \mathrm{MPa}, v=0 \cdot 2, a=1000, \alpha=12, \varepsilon_{\mathrm{d}}=10^{-4}, r=0 \cdot 5, q=7000 \mathrm{MPa}, w_{0}=26 \cdot 4 \mathrm{MPa}$
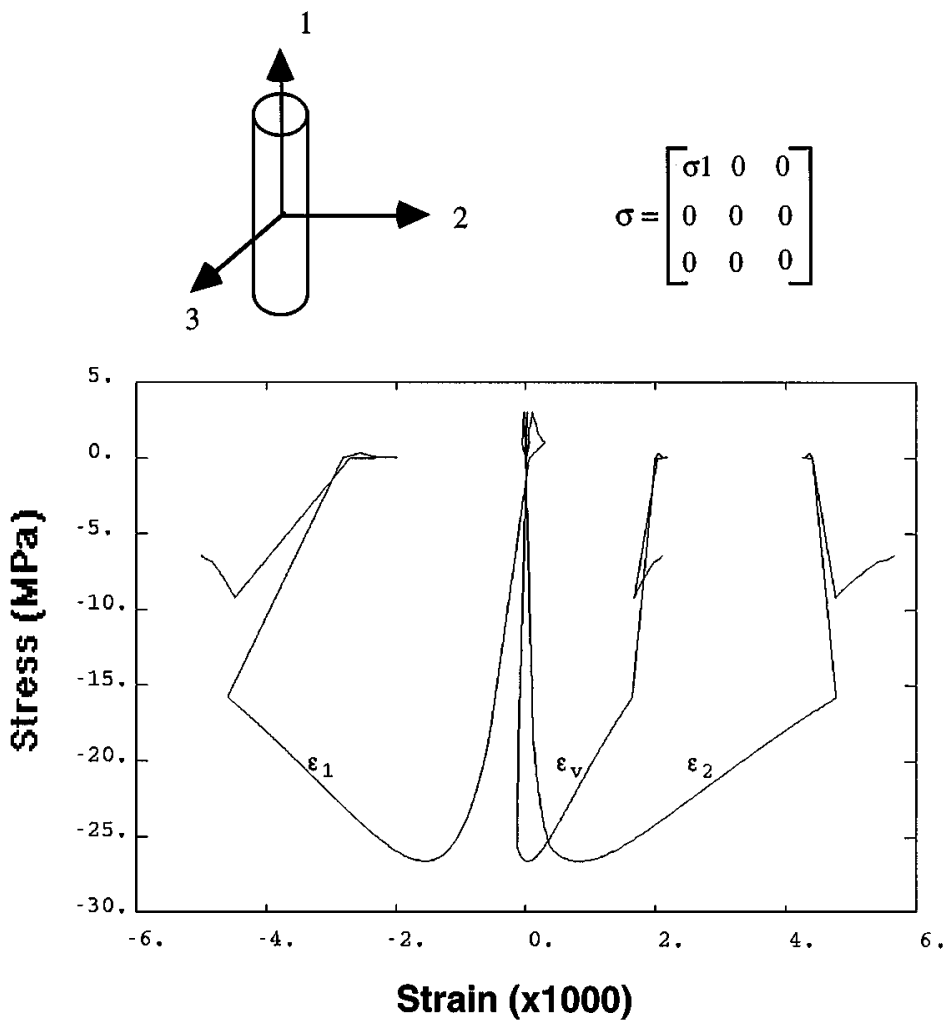

Figure 1. Uniaxial tension-compression response of the anisotropic model (longitudinal, transverse and volumetric strains as a function of the compressive stress) 
The anisotropic model reproduces quite well (qualitatively) the evolution of the longitudinal and of the transverse strains with the stress. With the isotropic model, that is assuming that the damage surface in equation (3) is a sphere, the same good description of the axial stress-axial strain curve would be obtained with the same model parameters. The axial stress-transverse strain curve would be, however, different because the elastic Poisson's ratio of the material would not be affected by damage.

The anisotropic model and the isotropic model have been implemented in the finite element code Castem 2000. Given the strain and the strain increment, the plastic strain increment is computed first. Because it depends on the effective stress only, the plastic strain increment is independent of damage. We have used for this a classical return mapping algorithm. ${ }^{30,31}$ The plane stress constraint is added in the computation of the plastic multiplier. ${ }^{32}$ Once the increment of plastic strain has been computed, the incremental damage is computed explicitly from equations $(5,6)$ and the new state of stress is obtained from equation (4). It is important to note that the plane stress conditions holds for the stress and the effective stress at the same time: let us assume that the plane stress constraint is $\sigma_{33}=0$. Equation (4) provides the relationship between the effective stress and this stress component which can be computed with a specific choice of the strain tensor:

$$
\begin{aligned}
\varepsilon^{*} & =\left[\begin{array}{lll}
0 & 0 & 0 \\
0 & 0 & 0 \\
0 & 0 & 1
\end{array}\right] \\
\frac{4 \pi}{3} \sigma_{33} & =\int_{S}\left(\left[(1-d(n)) \sigma_{33}^{t} n_{3}\right] \cdot \varepsilon_{33}^{*} n_{3}\right) \mathrm{d} \Omega=\sigma_{33}^{t} \int_{S}\left(\left[(1-d(n)) n_{3}\right] \cdot n_{3}\right) \mathrm{d} \Omega
\end{aligned}
$$

Therefore, if the plane stress constraint is satisfied for the effective stress, it is automatically satisfied for the stress in the damaged material.

The finite element code Castem 2000 uses a modified Newton-Raphson algorithm for the iterations towards equilibrium at the structural level. Therefore, it was not necessary to compute a consistent tangent operator for each constitutive relation as the stiffness used during the iterations is always the initial stiffness matrix of the structure. This computational algorithm may not be the optimal choice in terms of robustness and speed, however the issue of deriving a consistent tangent operator for this type of plastic-damage model has not been treated in this study.

\section{FINITE ELEMENT COMPUTATIONS AND COMPARISONS}

We are now going to compare the isotropic and anisotropic models on three types of structural analyses. At the level of the constitutive relations, a comparison has already been performed by Fichant et al. ${ }^{22}$ revealing that the shear response of the anisotropic damage model differs substantially from that of the isotropic one. This observation was based on the analysis of the material response to a strongly non-radial loading history proposed by William et $a l^{33}$ For situations where the loading history does not yield severe non-radial stress or strain histories, we will see that the situation may be quite different.

\subsection{Single-edge notched beam}

The first comparison deals with the single-edge notched concrete beam tested by Schlangen. ${ }^{34}$ This type of experiment has been simulated in the literature using smeared crack models and 
plasticity based models. ${ }^{16,35}$ The geometry of the beam and loading apparatus are schematized in Figure 2a. The notch depth in the centre of the beam is $20 \mathrm{~mm}$ and the notch width is $5 \mathrm{~mm}$. The load $F$ is applied on the testing apparatus so that the point load close to the notch is $F_{1}=10 / 11 F$ and the point load near the beam end is $F_{2}=1 / 11 F$. The material properties used in the simulations are the same as those chosen in Feenstra's analysis. ${ }^{35}$ They are indicated along with the model parameters in Table I. Figure $2 \mathrm{~b}$ shows the finite element mesh used for the analysis. It is composed of constant strain triangles. Figure 3 shows the plot of the applied load $F$ vs. the crack mouth sliding displacement (CMSD). We have plotted in this figure the experimental data, the computations performed with the isotropic and anisotropic plastic damage models and with the rotating crack model. ${ }^{35}$ Considering the experimental dispersion, the three predictions are quite equivalent, except for the tail of the curve which could not be reproduced with the damage models. Figure 4 shows the distribution of damage at the end of the computations. For the anisotropic damage model, we have plotted in Figure $4 \mathrm{~b}$ and in further calculations the measure of damage $D$ defined as

$$
D=\sqrt{\frac{1}{3}\left[d_{11}^{2}+d_{22}^{2}+d_{12}^{2}\right]}
$$

which provides an indication of the overall intensity of damage that is not attached to a specific direction. The two models predict a curved crack propagation with a small difference. The distribution of damage is more aligned with the vertical axis with the isotropic model than with the anisotropic one. It should be noted that, the two models are sensitive to mesh alignment when damage localises to form a crack. The regularisation employed here avoids mesh size dependence but not mesh alignment effects. Therefore, it is difficult to compare with the experiments. The finite element mesh, however, has been designed so that the actual crack path is approximately recovered by both computations.
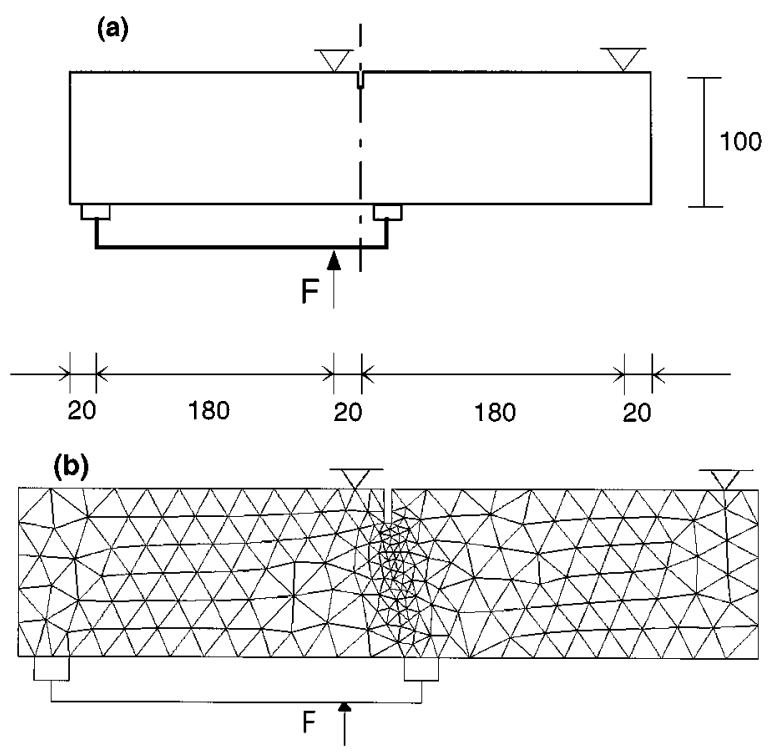

Figure 2. Single-edged notched beam: (a) geometry and loads (dimensions in $\mathrm{mm}$ ); (b) finite element mesh 
Table I. Material properties in the single-edged notched specimen
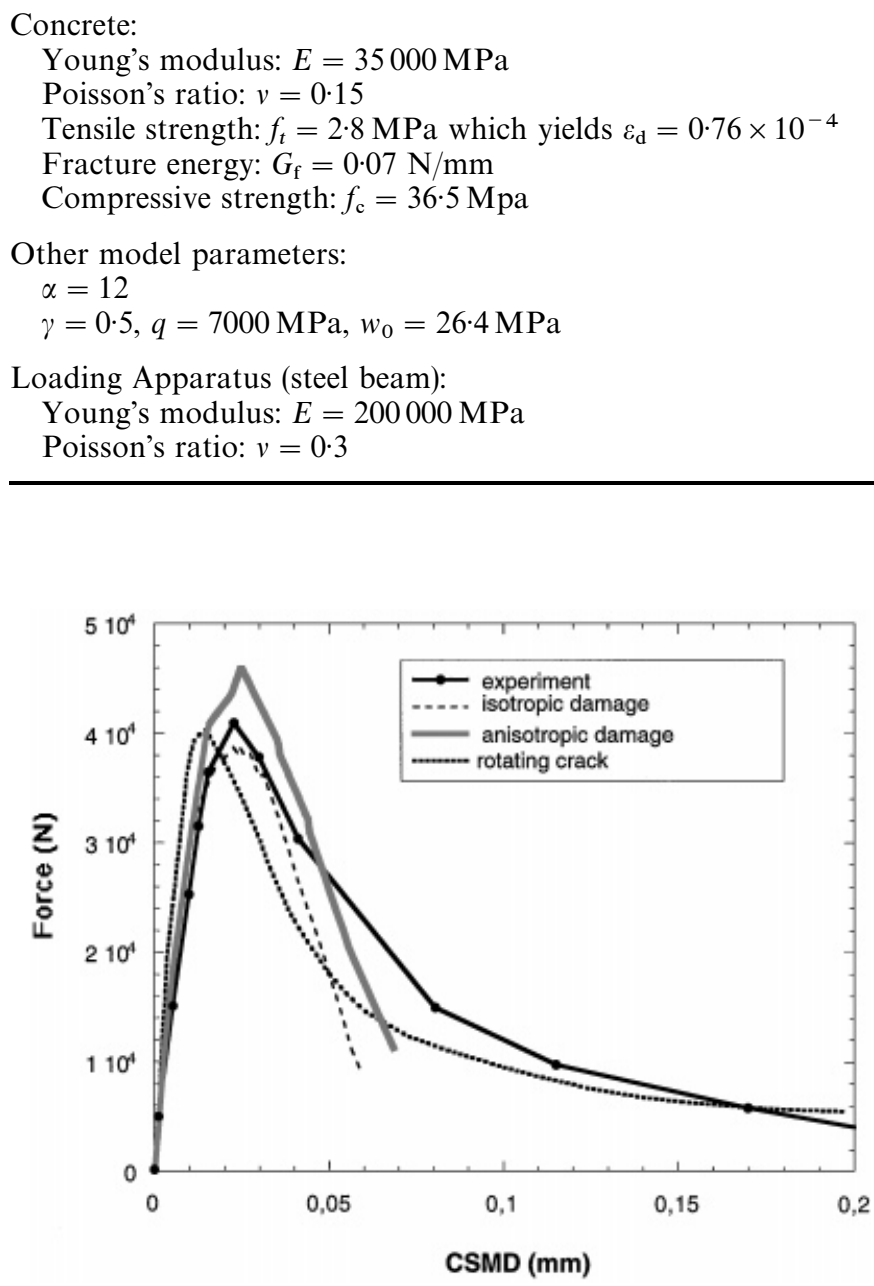

Figure 3. Single-edged notched beam: load vs. CMSD response

In this experiment, damage essentially occurs due to extensions. The two damage models provide the same material response in uniaxial tension, therefore it is not surprising that the models provide close results.

\subsection{Compression-shear experiments}

Compression-shear experiments have been performed on plain concrete I-shaped panels. ${ }^{36}$ The geometry of the panels and the loading system are shown in Figure 5a. The panel thickness is $60 \mathrm{~mm}$. Notches were cut on the specimens in order to control crack propagation and to avoid 


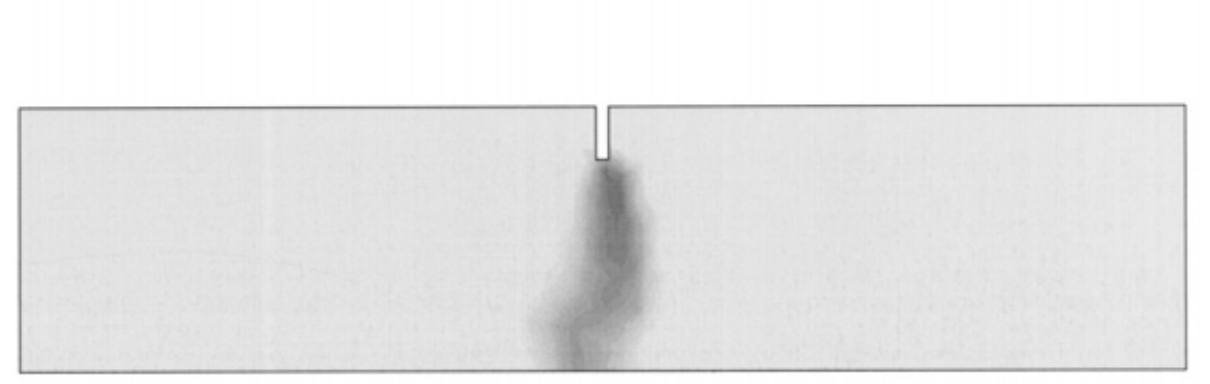

(a)

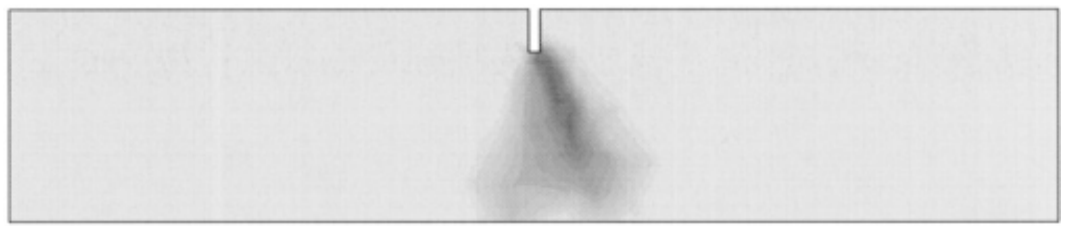

(b)

Figure 4. Single-edged notched beam: (a) distribution of damage with the isotropic model; (b) distribution of damage with the anisotropic model
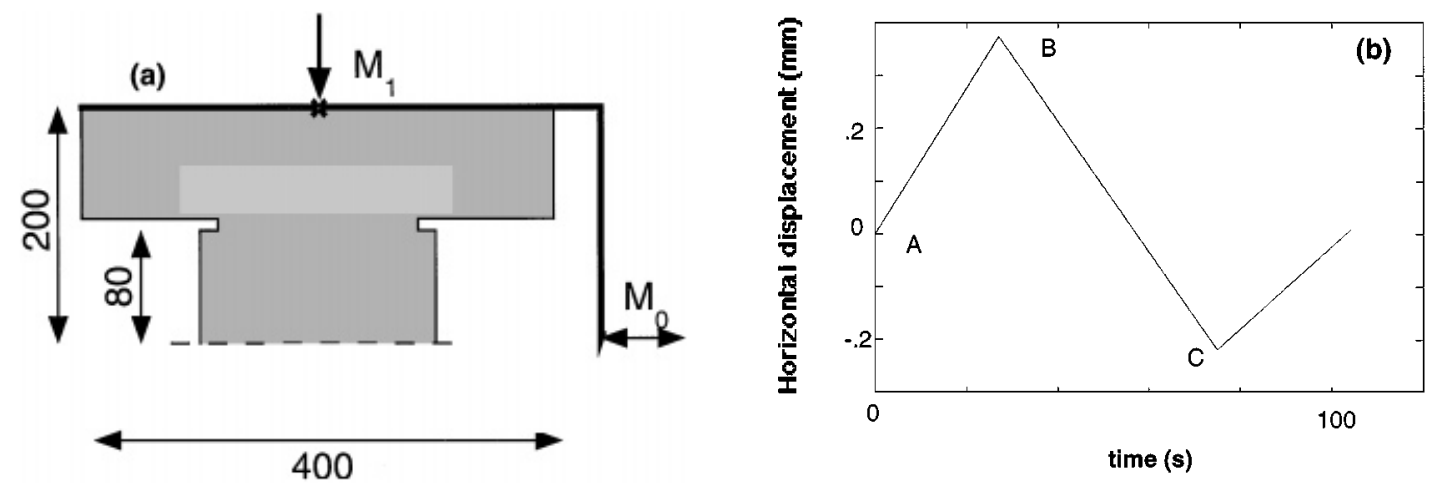

Figure 5. Compression-shear test: (a) specimens tested (dimensions in mm); (b) applied shear displacement history (the compression force is constant)

multiple cracking as much as possible. The tests were designed so that diagonal shear cracks propagate in the specimens subjected to alternated shear loads.

The biaxial load system shown in Figure 5a has been used. The vertical load, denoted $M_{1}$ in Figure 5a was applied with two hydraulic jacks and the lateral loads denoted as $M_{0}$ were applied with another pair of jacks. The vertical compression force was constrained to remain constant $(75 \mathrm{kN})$. The horizontal loads were applied under displacement (stroke) controlled conditions according to a history of displacements shown in Figure 5b. Loads and displacements were monitored with the load cells on each jack, the internal LVDTs in each jack, and additional 
transducers measuring the vertical and horizontal displacements of the specimen top and bottom faces. Figure 6 shows a schematic view of testing system and location of the LVDTs.

Table II shows the material properties of concrete and the corresponding model parameters. The plate was discretized with four-noded quadrilaterals. Only one-half of the plate was considered with the central symmetry of the displacements. Figure 7 shows the comparison of the horizontal load vs. applied (stroke) displacement between the experiment and the two predictions of the isotropic and anisotropic damage models. Again, the numerical predictions are quite similar. Figure 8 shows the distributions of damage. Figure 8a shows the distribution of damage

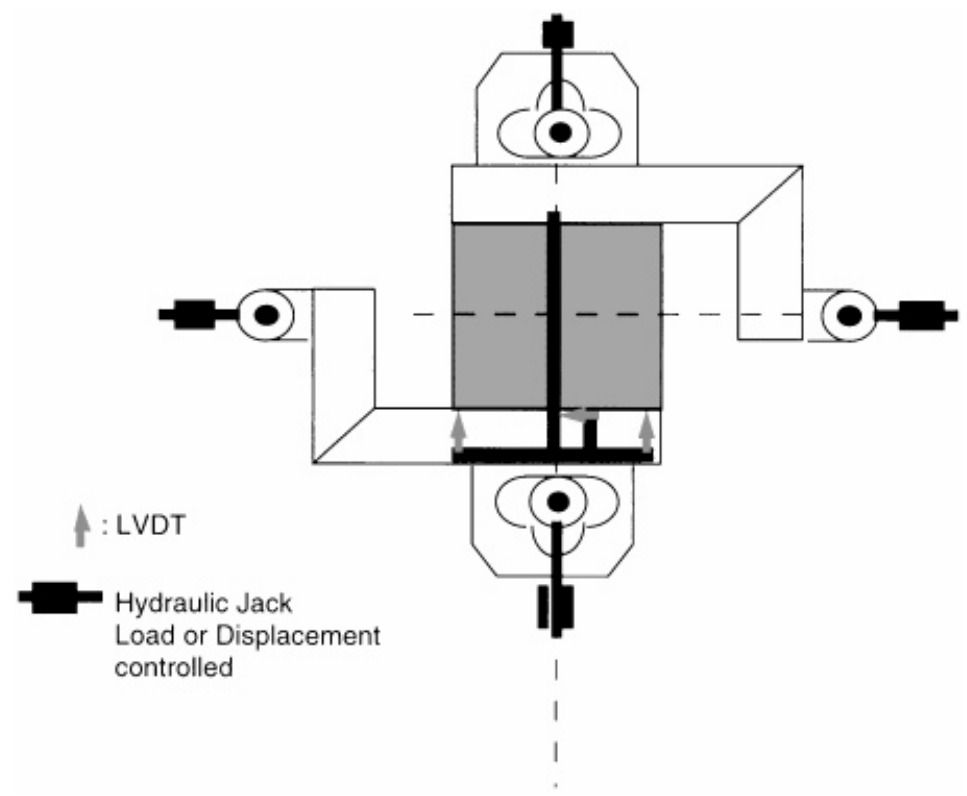

Figure 6. Compression-shear test: testing system and location of the transducers

Table II. Material properties in the compression shear specimen

Concrete:

Young's modulus: $E=35000 \mathrm{MPa}$

Poisson's ratio: $v=0 \cdot 15$

Tensile strength: $f_{t}=2.8 \mathrm{MPa}$ which yields $\varepsilon_{\mathrm{d}}=0.76 \times 10^{-4}$

Fracture energy: $G_{\mathrm{f}}=0.07 \mathrm{~N} / \mathrm{mm}$

Compressive strength: $f_{\mathrm{c}}=36.5 \mathrm{MPA}$

Other model parameters:

$$
\begin{aligned}
& \alpha=12 \\
& \gamma=0.5, q=7000 \mathrm{MPa}, w_{0}=26 \cdot 4 \mathrm{MPa}
\end{aligned}
$$

Loading Apparatus (steel beam):

Young's modulus: $E=200000 \mathrm{MPa}$

Poisson's ratio: $v=0 \cdot 3$ 
computed with the anisotropic model at point $\mathrm{B}$ of the loading history and Figures $8 \mathrm{~b}$ and $8 \mathrm{c}$ show the distribution of damage at the end of the load cycle for the two models. In both simulations, two independent diagonal crack systems develop in the plate, same as in the experiments. The first one when the horizontal load is negative and the second one when it becomes positive.

Although the isotropic damage model does not contain any directional information, it provides the same prediction of the crack system. This is, no doubt, due to the crack closure effect. Recall

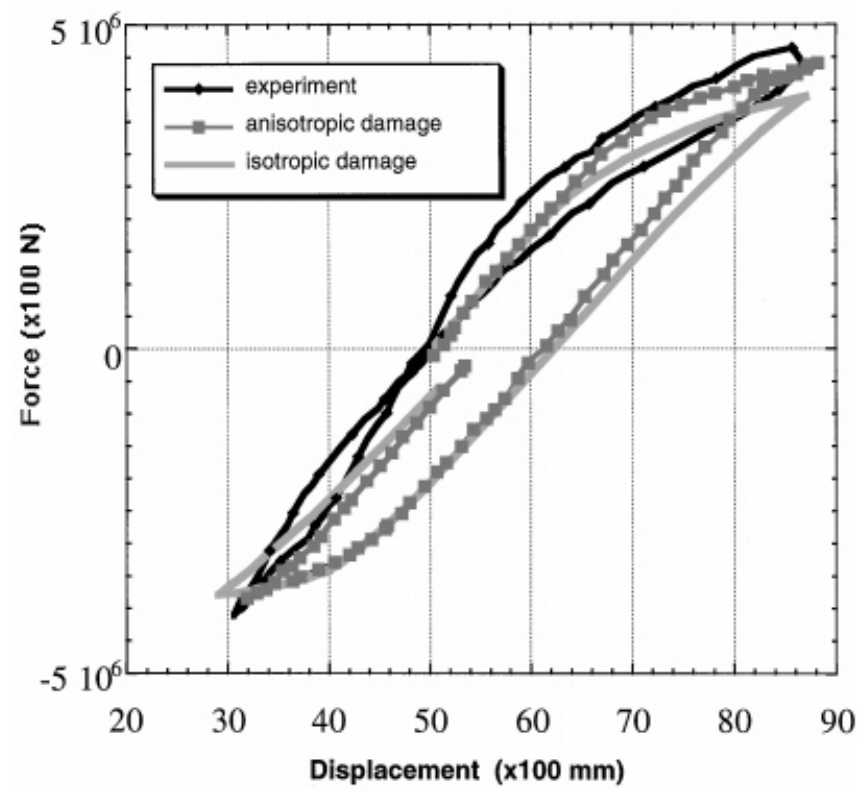

Figure 7. Compression-shear test: experimental and predicted load vs. displacement responses

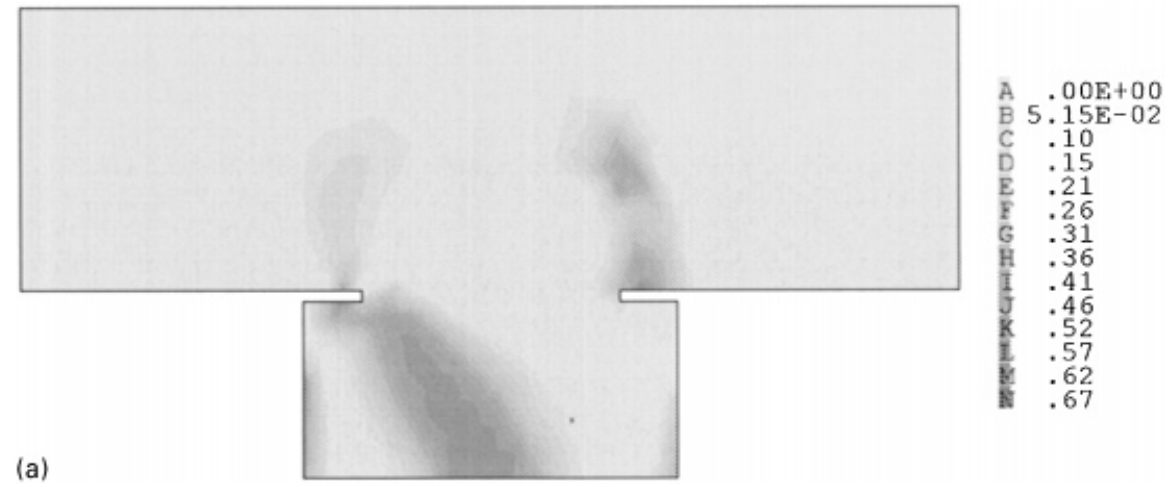

Figure 8. Compression-shear test: (a) map of damage at point B of the loading history with the anisotropic model; (b) map of damage at the end of the loading history with the anisotropic model; (c) map of damage at the end of the loading history with the isotropic model 

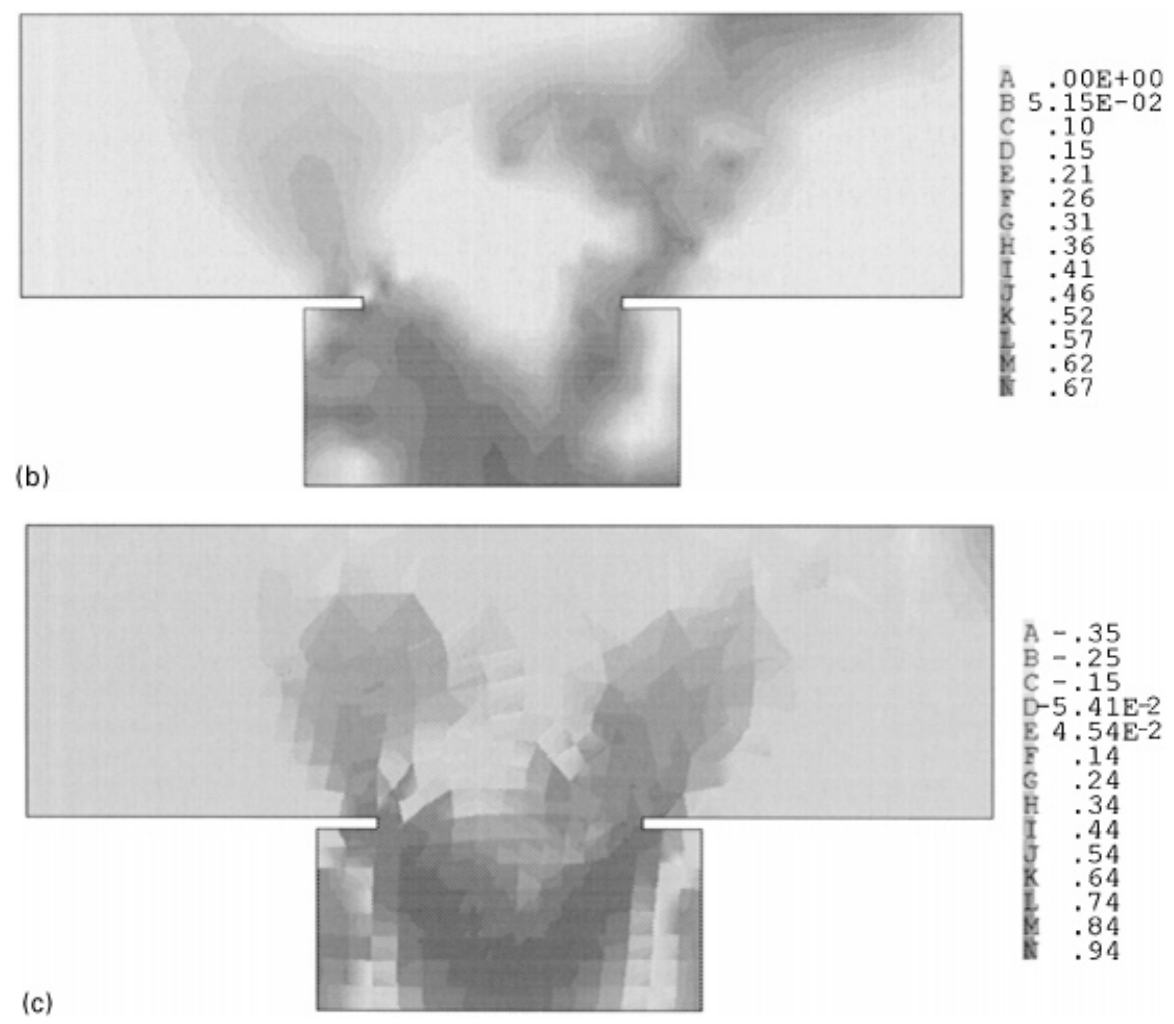

Figure 8. Continued

that the plate is subjected to a constant in plane vertical compression. When the horizontal load changes sign, the principal stresses show change of sign too. The principal directions of the stresses rotate with an expected amplitude of $45^{\circ}$ (from pure compression to pure shear). The change of sign of the principal stresses is much more important than damage induced anisotropy because it occurs under compressive loading where damage does not affect the response of the specimen. Damage deactivation occurs and the material stiffness is locally restored. Crack closure and damage deactivation confer in fact some directional information to the isotropic material model. Substitution of equation (13) in equation (4) yields to foregoing relation between the stress and the effective stress with the isotropic model:

$$
\sigma_{i j}=(1-d)\left\langle\sigma_{i j}\right\rangle_{+}^{t}+\left(1-d_{\mathrm{c}}\right)\left\langle\sigma_{i j}\right\rangle_{-}^{t}
$$

If we consider a simple shear problem where the (positive) effective shear stress is $\sigma_{t}$, we obtain under plane stress conditions:

$$
\sigma=\left[\begin{array}{ccc}
(1-d) \sigma_{t} & 0 & 0 \\
0 & -\left(1-d_{\mathrm{c}}\right) \sigma_{t} & 0 \\
0 & 0 & 0
\end{array}\right]
$$


Clearly, the elastic stiffness of the material will be isotropic only if $d=d_{\mathrm{c}}$ which is never the case according to equation (14), except when $d_{i}=1$ (material completely damaged). Therefore, crack closure effect, in the isotropic damage model, yields an orthotropic elastic stiffness operator which contains the loading directions. In this example, the isotropic and anisotropic models provide close predictions because of crack closure and of the inherent damage deactivation.

\subsection{Double-edged notched specimen}

On tension-shear problems, the predictions of the two models should not be as close because damage deactivation may not occur. In order to investigate this possibility, computations on the double edged notched specimens tested by Nooru-Mohamed ${ }^{37}$ have been performed. Figure 9a shows the specimen geometry of the plain concrete panels tested. Their thickness was $50 \mathrm{~mm}$. The panels were loaded by a shear force denoted as $P_{\mathrm{s}}$ first. This load was kept constant while uniaxial tension was applied to the specimen. The tensile force $P$ was controlled by the relative tensile displacement $\delta$ measured in between two points $\mathrm{A}$ and $\mathrm{A}^{\prime}$ as shown in the figure.

In order to focus on the differences between the two damage models, we have removed plasticity from the constitutive relations. Since plasticity is essentially intended to capture the inelastic strain which develop in mainly compression, it should not be important in the present
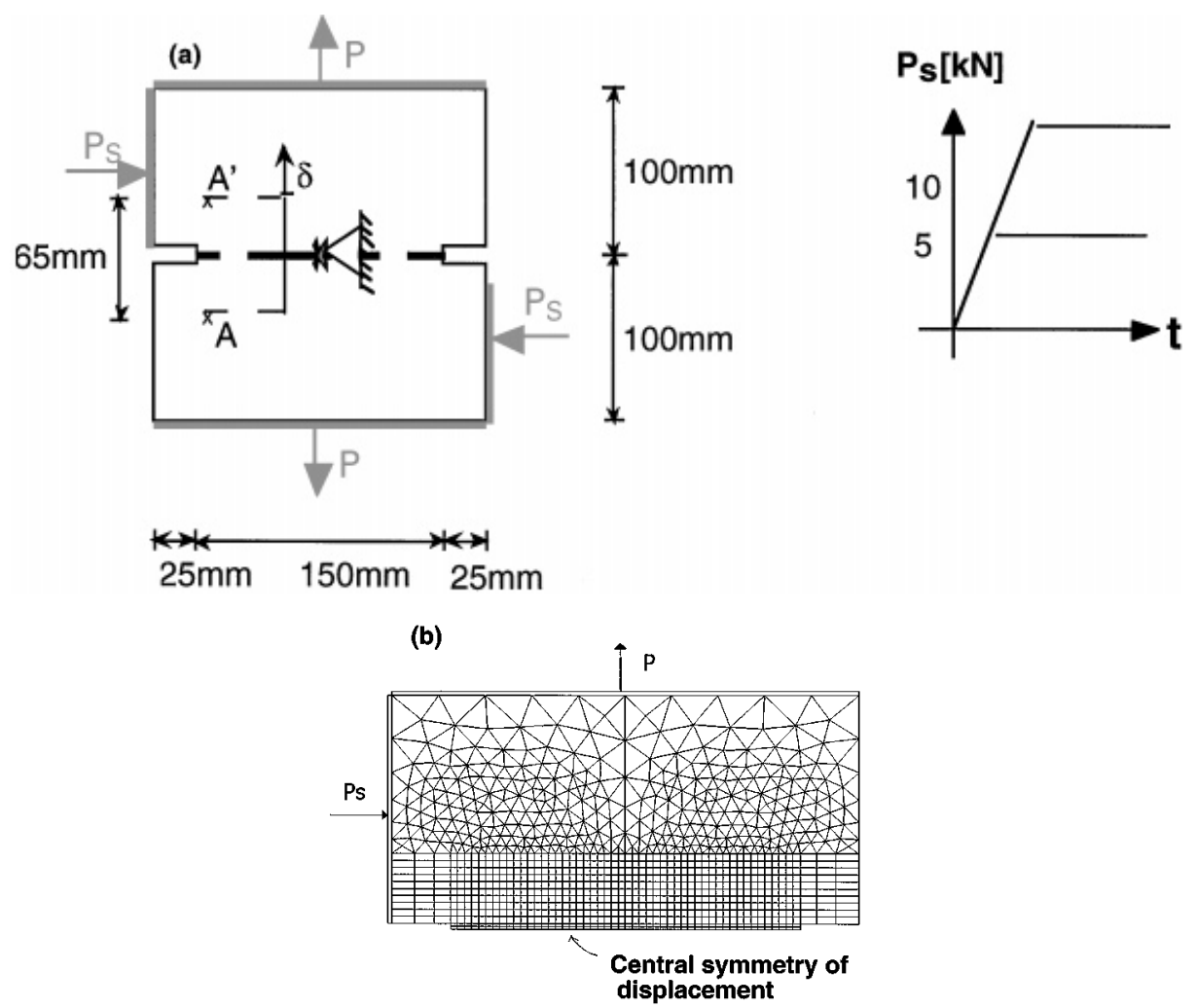

Figure 9. Double-edged notched specimen: (a) geometry and loads; (b) finite element mesh 
Table III. Material properties in the double-edged notched specimen

Concrete:

Young's modulus: $E=30000 \mathrm{MPa}$

Poisson's ratio: $v=0 \cdot 2$

Tensile strength: $f_{t}=3 \mathrm{MPa}$ which yields $\varepsilon_{\mathrm{d}}=1 \times 10^{-4}$

Fracture energy: $G_{\mathrm{f}}=0.01 \mathrm{~N} / \mathrm{mm}$

Compressive strength: $f_{\mathrm{c}}=36.5 \mathrm{MPA}$

Other model parameters:

$\alpha=12$

Loading Apparatus (steel beam):

Young's modulus: $E=200000 \mathrm{MPa}$

Poisson's ratio: $v=0 \cdot 3$
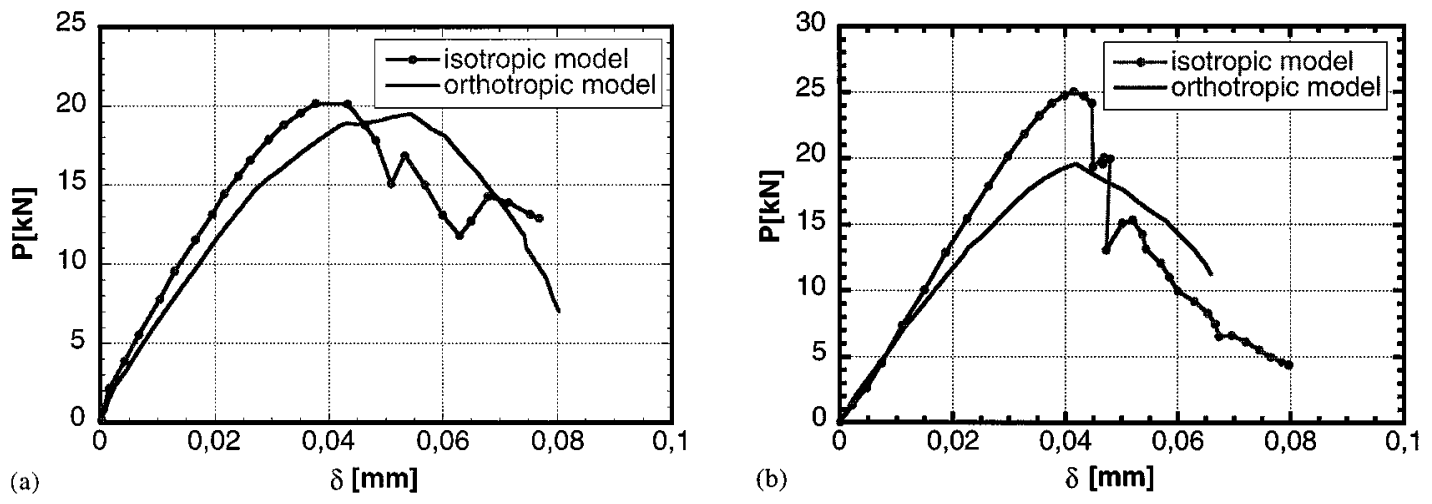

Figure 10. Double-edged notched specimen: (a) tensile load vs. vertical displacement for $P_{\mathrm{s}}=5 \mathrm{kN}$; (b) $P_{\mathrm{s}}=10 \mathrm{kN}$

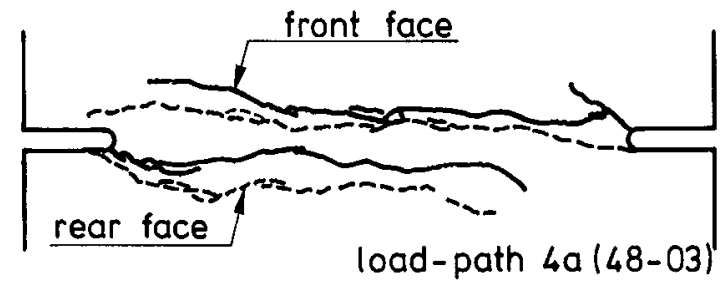

(a)

Figure 11. Double-edged notched specimen: (a) cracking observed for $P_{\mathrm{s}}=5 \mathrm{kN}$ (after Nooru-Mohamed, 1992); (b) damage according to the isotropic model for $P_{\mathrm{s}}=5 \mathrm{kN}$; (c) damage according to the anisotropic model for $P_{\mathrm{s}}=5 \mathrm{kN}$ 

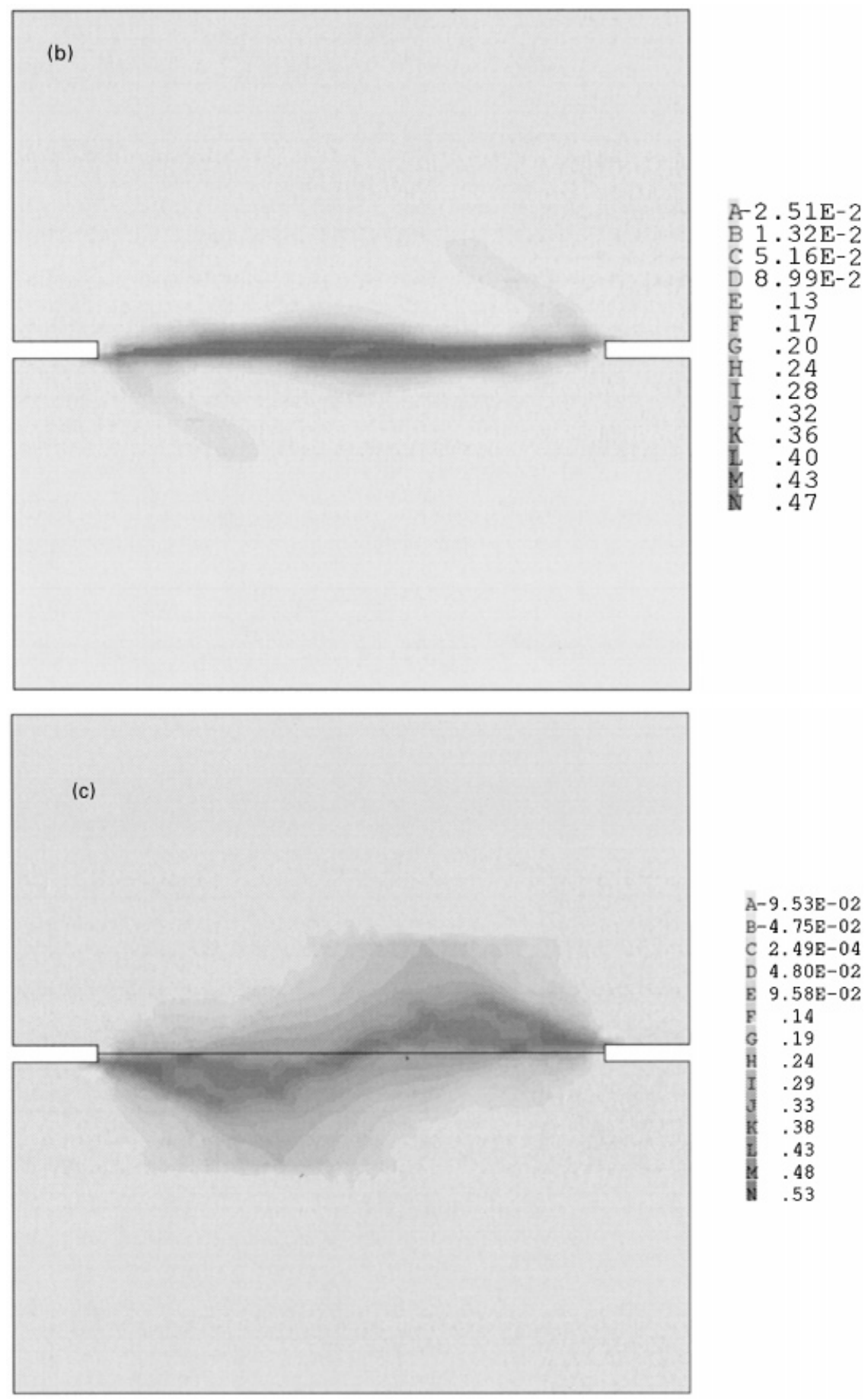
A- $9.53 \mathrm{E}-02$
B-4.75E-02
C $2.49 \mathrm{E}-04$
D $4.80 \mathrm{~B}-02$
E $9.58 \mathrm{E}-02$
F . .14
G .19
H. .24
I. .29
J. .33
.38
.43
.48
N. .53

Figure 11. Continued 
case where tension is the principal source of material non linearity. Table III shows the material properties of concrete and the model parameters used in the computations. Figure $9 \mathrm{~b}$ shows the finite element discretization. Note that the steel loading platens employed in the test were also represented in the finite element model.

Two tests have been considered with different values of the shear force: $P_{\mathrm{s}}=5 \mathrm{kN}$ and $P_{\mathrm{s}}=10 \mathrm{kN}$. Figure 10 shows the predictions according to the two constitutive relations. The maximum tensile loads are quite similar for the lowest shear force and the predictions of the two models differ when shear is increased. It is much demonstrating to compare the evolution of the maximum tensile force: the experimental data indicate that the maximum tensile force should

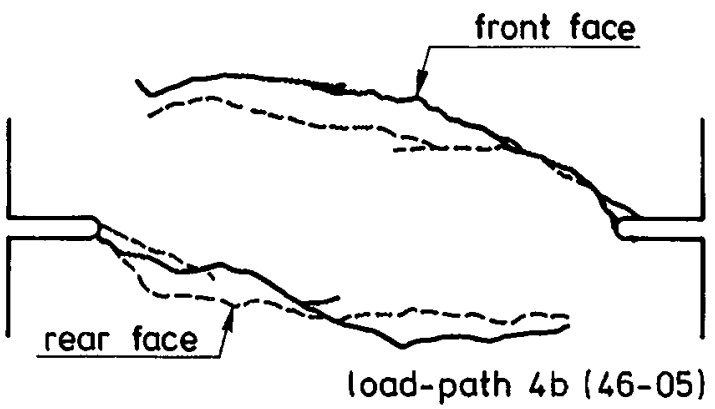

(a)

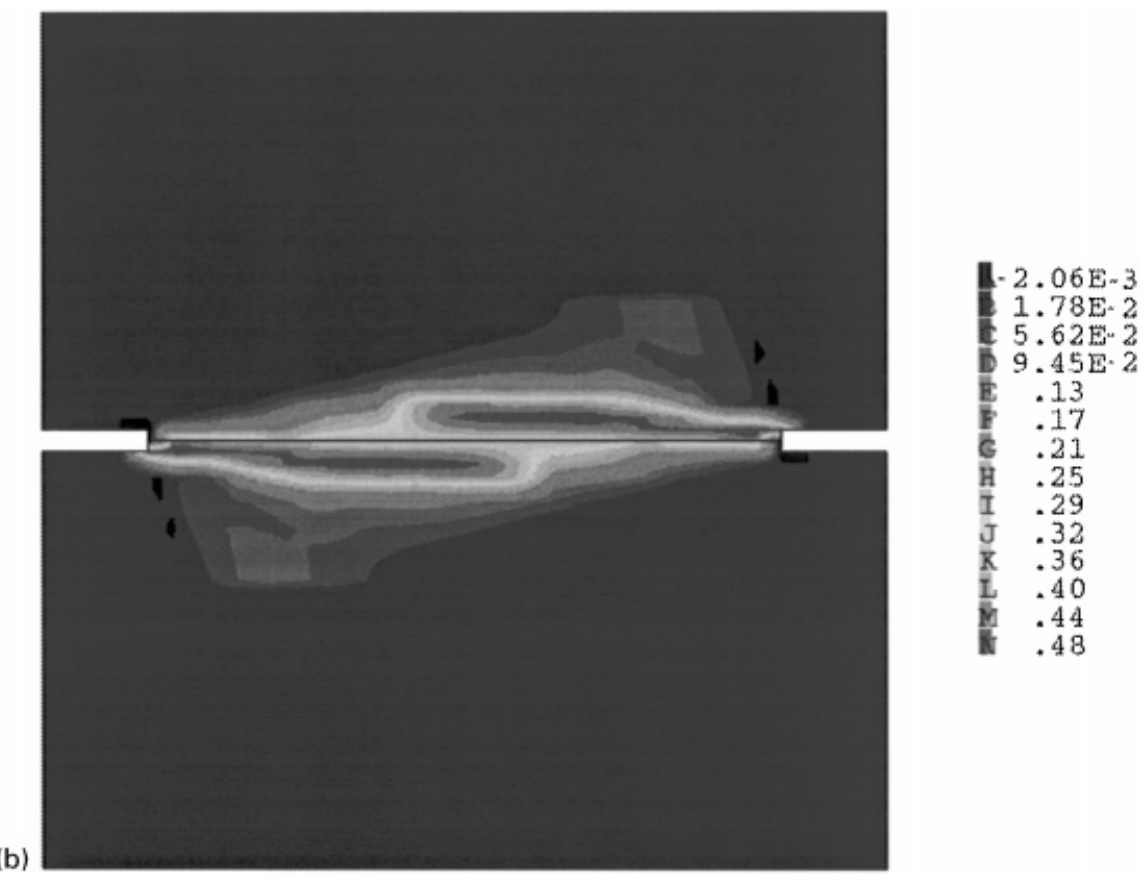

Figure 12. Double-edged notched specimen: (a) cracking observed for $P_{\mathrm{s}}=10 \mathrm{kN}$ (after Nooru-Mohamed, 1992); (b) damage according to the isotropic model for $P_{\mathrm{s}}=10 \mathrm{kN}$; (c) damage according to the anisotropic model for $P_{\mathrm{s}}=10 \mathrm{kN}$ 


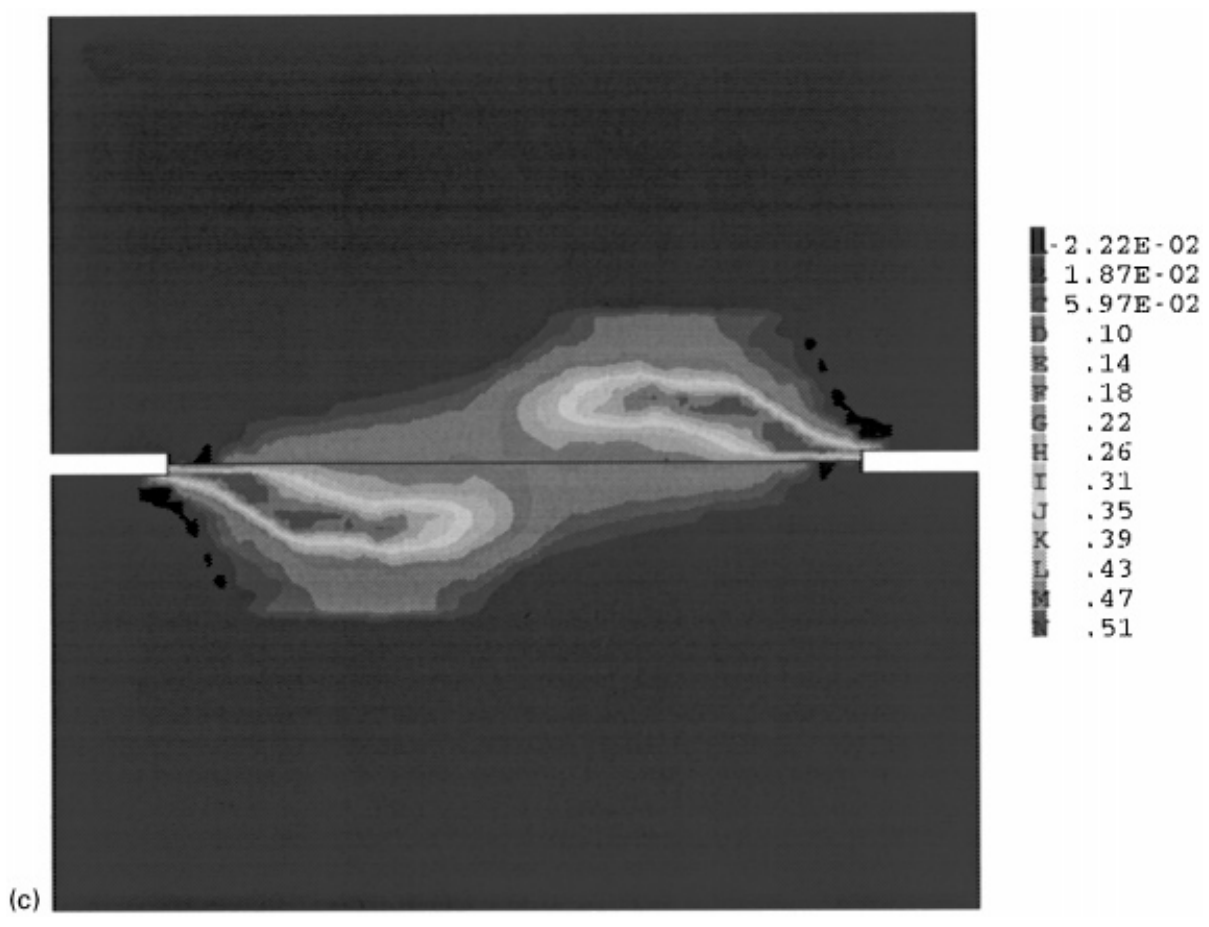

Figure 12. Continued

decrease by $15 \%$ as shear is increased. The computations with the isotropic damage model yield exactly the contrary. With the anisotropic model, there is a very slight decrease of the tensile load. The reason for these differences is better illustrated on the maps of damage (Figures 11 and 12). For the smallest shear load, horizontal cracks develop in the centre of the plate. Both models provide reasonably accurate predictions compared to the experiments. When $P_{\mathrm{s}}=10 \mathrm{kN}$, two curved cracks should develop according to the experimental observation. Still, the isotropic model predicts that horizontal cracks should propagate while the curved crack propagation is better approached with the anisotropic damage model. The difference observed on the failure modes explains that the maximum tensile force be different in the two computations. It is in this situation, on tension shear problems, where we found that the anisotropic model provides a substantially better prediction compared to the isotropic one.

\section{CONCLUSIONS}

Isotropic (scalar) damage models are simple to develop and can be easily fitted from uniaxial experiments. At the same time, damage-induced anisotropy is too delicate to characterize experimentally. It increases the number of model parameters to be experimentally determined, at least in the context of phenomenological model where damage is a second- or a fourth-order tensor. Although it is legitimate to argue that the definition of a damage variable should incorporate some directional information, it is interesting to sort out situations where an isotropic model may yield equally good predictions in structural analyses. 
In order to perform comparisons, we have started from a generic damage model which is a simplified version of the microplane model. Damage is defined through the relationship between the overall stress and the effective stress in the material. This relation is approximated through damage surfaces whose interpolation is fixed in advance and can be refined if there is a necessity. In order to avoid a potential bias due to the fitting of the model parameters, the isotropic and orthotropic damage model considered are based on the same set of parameters, identified from the same data. Plasticity is coupled to damage in order to capture inelastic residual strains which occur essentially when the material is subjected to compression. Damage deactivation is also incorporated in the models.

In structural analyses and when the failure mode is essentially controlled by uniaxial tension, we found that damage-induced anisotropy is not really required. In fact, damage deactivation due to crack closure is more important as it introduces anisotropy of the elastic stiffness. Damage induced anisotropy seems important when the material is locally subjected to multiaxial extension, e.g. in shear-tension problems. It is also expected that anisotropy is of central importance in situations where the loading history is severely non radial with an incremental growth of damage. This particular point remains to be validated with comparisons on structural analyses. In this contribution, we intended to compare models with the same evolution of damage. It should be pointed out that other types of damage growth relations might yield better descriptions of the tension-shear response of the material within the assumption of isotropic damage.

\section{REFERENCES}

1. S. P. Shah and A. Maji, 'Experimental observation of cracking and damage', in Cracking and Damage, J. Mazars and Z. P. Bazant, eds, Elsevier, Amsterdam, 1989, pp. 15-29.

2. J. M. Torrenti, J. Desrues, P. Acker and C. Boulay, 'Application of strereophotogrammetry to the strain localisation in concrete compression', in Cracking and Damage, J. Mazars and Z. P. Bazant, eds, Elsevier, Amsterdam, 1989, pp. 30-41.

3. J. Lemaitre, A Course on Damage Mechanics, Springer, Berlin, 1992.

4. D. Krajcinovic and G. U. Fonseka, 'The continuous damage theory of brittle materials', J. Appl. Mech. ASME, 48, 809-824, 1981.

5. F. Sidoroff, 'Description of anisotropic damage application to elasticity', in Proc. IUTAM Symp. on Physical Nonlinearities in Structural Mechanics, J. Hult and J. Lemaitre, eds, Springer, Berlin, 1981, pp. 237-244.

6. J. L. Chaboche, P. M. Lesne and J. F. Maire, 'Phenomenological damage mechanics of brittle materials with description of the unilateral damage effect', in Fracture and Damage in Quasibrittle Structures, Z. P. Bazant et al., eds, E\&FN Spon Pubs, London, 1994, pp. 75-84.

7. J. Mazars and G. Pijaudier-Cabot, 'Continuum damage theory - application to concrete', J. Engng. Mech. ASCE, 115, 345-365, 1989.

8. A. Dragon and Z. Mroz, 'A continuum model for plastic-brittle behaviour of rock and concrete', Int. J. Engng. Sci., 17, 121-137, (1979).

9. Y. Berthaud, C. Laborderie and S. Ramtani, Damage Modelling and Crack Closure Effects, Damage Mechanics in Engng. Materials, J. W. Ju et al., eds, ASME AMD, Vol. 109, 1990, pp. 263-276.

10. K. C. Valanis, 'A global damage theory and the hyperbolicity of the wave problem', J. Appl. Mech. ASME, 58, 311-316 (1991).

11. M. Ortiz, 'A constitutive theory for the inelastic behaviour of concrete', Mech. Mater., 4, 67-93 (1985).

12. J. C. Simo and J. W. Ju, 'Strain- and stress-based continuum damage models - I formulation', Int. J. Solids Struct., 23, 821-840 (1987).

13. S. Yazdani and H. L. Schreyer, 'Combined plasticity and damage mechanics model for plain concrete', J. Engng. Mech. ASCE, 116, 1435-1450 (1990).

14. I. Carol, E. Rizzi and K. William, 'A unified description of elastic degradation and damage based on a loading surface', Int. J. Solids Struct., 31, 2835-2865 (1994).

15. S. Govindjee, G. J. Kay and J. C. Simo, 'Anisotropic modelling and numerical simulation of brittle damage in concrete', Int. J. Numer. Meth. Engng., 38, 3611-3633 (1995). 
16. J. G. Rots, 'Computational modelling of concrete fracture', Doctoral Dissertation, Delft University of Technology, The Netherlands, 1988.

17. M. Francois, G. Geymonat and Y. Berthaud, Determination of the symmetries of an experimentally determined stiffness tensor: application to acoustic measurements, Presented at the 34th. SES Conf. Tempe, Arizona, Int. J. Solids Struct., 35, 4091-4106 (1998).

18. P. Ladeveze, 'Sur une théorie de l'endommagement anisotrope', Int. Report No. 34, Laboratoire de Mécanique et Technologie, Cachan, France; Presented at the CNRS Int. Colloquium on Failure Criteria of Structured Media, Villars de Lans, June 1983, France; published in English in the Proc. Failure Criteria of Structured Media, J. P. Boehler, ed., Balkema, Rotterdam, 1993, pp. 355-364.

19. Z. P. Bazant and J. Ozbolt, 'Nonlocal microplane model for fracture, damage and size effect in structures', J. Engng. Mech. ASCE, 116, 2485-2505 (1990).

20. I. Carol, Z. P. Bazant and P. C. Prat, 'Geometrical damage tensor based on microplane model', J. Engng. Mech. ASCE, 117, 2429-2448 (1991).

21. I. Carol and Z. P. Bazant, 'Damage and plasticity in microplane theory', Int. J. Solids Struct., 39, 3807-3835 (1997).

22. S. Fichant, G. Pijaudier-Cabot and C. La Borderie, 'Continuum damage modelling: approximation of crack induced anisotropy', Mech. Res. Commun., 24, 109-114 (1997).

23. S. Fichant, 'Endommagement et anisotropie induite du béton de structures, Modélisations approchées', thèse de Doctorat de l'ENS Cachan, Cachan, France, 1996.

24. Z. P. Bazant and P. C. Prat, 'Microplane model for brittle-plastic material I: theory', J. Engng. Mech. ASCE, 114, 1672-1702 (1988).

25. J. W. Ju, 'On energy-based coupled elastoplastic damage theories: constitutive modelling and computational aspects', Int. J. Solids Struct., 25, 803-833 (1989).

26. J. Lemaitre, 'How to use damage mechanics', Nucl. Engng. Des., 80, 233-245 (1984).

27. A. Benallal, R. Billardon and J. Lemaitre, 'Continuum damage mechanics and local approach to fracture: numerical procedures', Comput. Meth. Appl. Mech. Engng., 92, 141-155 (1991).

28. A. Nadai, Theory of Flow and Fracture of Solids, Vol. 1, 2nd ed., McGraw-Hill, New York, 1950, p. 572.

29. A. Hillerborg, M. Modeer, and P. E. Petersson, 'Analysis of crack formation and crack growth in concrete by means of fracture mechanics and finite elements, cement and concrete research', 6, 773-782 (1976).

30. M. Oritz, and J. C. Simo 'An analysis of a new class of integration algorithm for elastoplastic constitutive relations', Int. J. Numer. Meth. Engng., 23, 353-366 (1986).

31. J. C. Simo, and R. L. Taylor, 'Return mapping algorithm for plane stress elastoplasticity', Int. J. Numer. Meth. Engng., 22, 649-670 (1986).

32. N. Aravas, 'On the numerical integration of a class of pressure dependent plasticity models', Int. J. Numer. Meth. Engng., 24, 1395-1416 (1987).

33. K. William, E. Pramono and S. Sture, 'Fundamental issues of smeared crack models', Proc. Int. Conf. of Fracture and Rocks, S. P. Shah and S. E. Swartz, eds, Springer, Berlin, 1986, pp. 142-157.

34. E. Schlangen, 'Experimental and numerical analysis of fracture processes in concrete', Doctoral Dissertation, Delft University of Technology, The Netherlands, 1993.

35. P. H. Feenstra, 'Computational aspects of biaxial stress in plain and reinforced concrete', Doctoral Dissertation, Delft University of Technology, The Netherlands, 1993.

36. J. L. Clément, S. Fichant, C. Laborderie, G. Pijaudier-Cabot and J. L. Tailhan, 'Experiments on pre-damaged specimens', Report of Brite-Euram project P-3275 “Failure Mechanics of Fibre-Reinforced Concrete and Pre-Damaged Structures", Laboratoire de Mécanique et Technologie, Cachan, France, 1994.

37. M. B. Nooru-Mohamed, 'Mixed-mode fracture of concrete: an experimental approach', Doctoral Dissertation, Delft University of Technology, The Netherlands, 1992. 